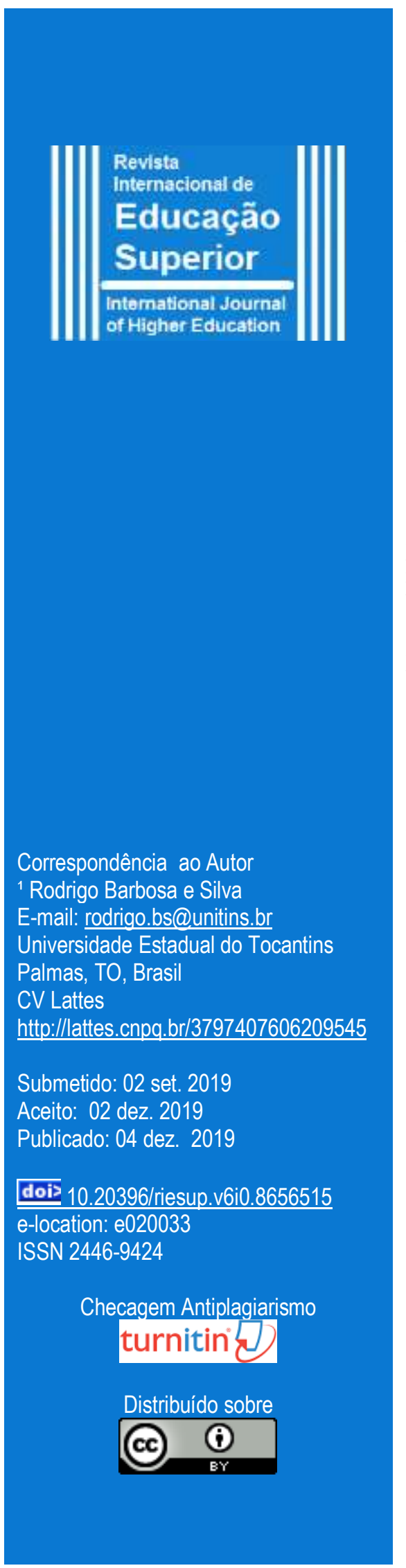

\title{
O Comitê de Ética em Pesquisa como Espaço de Formação Continuada do Professor Universitário
}

Rodrigo Barbosa e Silva ${ }^{1}$ https://orcid.org/0000-0001-6027-5821

Vida Kamila Pinheiro da Conceição (D.ttps://orcid.org/0000-0001-8296-4548

1,2 Universidade Estadual de Tocantins

\section{RESUMO}

Este artigo é fruto de uma reflexão sobre o trabalho docente desenvolvido em um Comitê de Ética em Pesquisa. O objetivo em pauta foi destacar o eixo da pesquisa como um dos elementos de formação profissional para docência do ensino superior por meio da avaliação ética de protocolos de pesquisa. Metodologicamente, atrelada a esta atuação profissional, foi realizada revisão de literatura que incluiu normativas e resoluções brasileiras sobre o compromisso ético no campo da pesquisa científica, além de obras que versam sobre alternativas de formação continuada de professores universitários. Concluímos que a eticidade perpassa pelos saberes pedagógicos constituídos também no processo de atuação e mediação docente no campo da pesquisa, haja vista ser este o modelo de formação para o magistério de nível superior preconizado no Brasil.

\section{PALAVRAS-CHAVE}

Magistério de ensino superior. Ética pedagógica. Docente em formação.

Correspondência ao Autor

Rodrigo Barbosa e Silva

mall. rodrigo.bs@unitins.br

Universidade Estadual do Tocantins

Palmas, TO, Brasi

CV Lattes

http://lattes.cnpq.br/3797407606209545

Submetido: 02 set. 2019

Aceito: 02 dez. 2019

Publicado: 04 dez. 2019

\section{doiæ $10.20396 /$ riesup.v6i0.8656515}

e-location: e020033

ISSN 2446-9424

hecagem Antiplagiarismo

Distribuído sobre 


\section{The Research Ethics Committee as a Space for Continuing Education of the University Professor}

\section{ABSTRACT}

This article is the result of a reflection on the teaching work developed in a Research Ethics Committee. The objective was to highlight the research axis as one of the elements of professional education for higher education teaching through the ethical evaluation of research protocols. Methodologically, linked to this professional performance, a literature review was carried out that included Brazilian norms and resolutions on the ethical commitment in the field of scientific research, as well as works that deal with alternatives for continuing education of university professors. We conclude that the ethics permeates the pedagogical knowledge constituted also in the process of acting and teaching mediation in the research field, given that this is the training model for the higher level teaching professed in Brazil.

\section{KEYWORDS}

Academic teaching personnel. Ethics of science. Teacher education.

\section{El Comité de Ética en Investigación como Espacio para la Educación Continua del Profesor Universitário}

\section{RESUMEN}

Este artículo es el resultado de una reflexión sobre el trabajo docente desarrollado en un Comité de Ética en Investigación. El objetivo era destacar el eje de investigación como uno de los elementos de la educación profesional para la enseñanza de la educación superior a través de la evaluación ética de los protocolos de investigación. Metodológicamente, vinculado a este desempeño profesional, se realizó una revisión de la literatura que incluyó normas y resoluciones brasileñas sobre el compromiso ético en el campo de la investigación científica, así como trabajos que abordan alternativas para la educación continua de los profesores universitarios. Llegamos a la conclusión de que la ética impregna el conocimiento pedagógico constituido también en el proceso de actuación y mediación docente en el campo de la investigación, dado que este es el modelo de formación para la enseñanza de nivel superior profesada en Brasil.

\section{PALABRAS CLAVE}

Enseñanza superior. Ética de la ciencia. Educación permanente. 


\section{Introdução}

É consenso entre as diversas áreas de conhecimento que o desenvolvimento social não pode ser dissociado do progresso científico. As descobertas e inovações acontecem como consequência da investigação de pesquisadores que, em inúmeros destes trabalhos, envolvem seres humanos como participante de pesquisa, direta ou indiretamente. É nesse ponto que se apresentam dois desafios às universidades no contexto dos projetos de pesquisa: o primeiro gira em torno da ética em pesquisa envolvendo seres humanos. Atrelado a isso, a percepção de que os espaços de avaliação ética destes projetos podem ser configurados como ambientes de aprendizagem colaborativa entre os professores que deles fazem parte.

As constantes discussões a respeito dos direitos humanos e a atual preocupação com o respeito à dignidade humana (PIOVESAN, 2016; SARLET, 2015) podem ser fatores que impulsionam a criação de Comitês de Ética em Pesquisa com Seres Humanos (CEP) nas universidades brasileiras, apesar da regulamentação nesse sentido possuir mais de vinte anos.

A sustentação para as nossas reflexões sobre a temática, e a consequente elaboração deste artigo, veio por meio da criação de um CEP na Universidade Estadual do Tocantins (UNITINS). A vivência neste processo nos possibilitou problematizar o papel destes comitês no processo de formação continuada de professores universitários. Para tanto, lançamos mão de uma pergunta norteadora para as nossas reflexões: de que forma a atuação em um comitê de ética colabora com a formação deste profissional para o exercício do magistério de nível superior?

A metodologia direcionou-se à análise bibliográfica em duas frentes. A primeira perfez um percurso histórico de publicações referentes ao contexto da pesquisa envolvendo seres humanos no Brasil e se apoiou em normativas e resoluções internacionais e nacionais sobre o compromisso ético visando o progresso da ciência atrelado ao desenvolvimento humano-social. A segunda, por sua vez, focou os espaços alternativos de formação da docência universitária. Para tanto, Nóvoa (2002), Severino (2009) e Cunha (2008), entre outros, colaboraram para o destaque da necessidade de um processo contínuo de avaliação e ressignificação do papel do professor no século XXI, especificamente, no que tange ao ato de lecionar para um público jovem que (re)constrói suas identidades permanentemente sob a conjuntura da desterritorialização, consequência da presença da internet na contemporaneidade. A experiência dos autores no tema abordado, principalmente durante os anos de atuação no mencionado comitê de ética, também contribuiu para que pudéssemos estruturar a relação construída neste artigo - protocolos de eticidade na pesquisa e o exercício do magistério em sala de aula de cursos superiores.

Este estudo apresenta um caráter qualitativo em que se buscou refletir sobre o perfil do professor universitário exigido na contemporaneidade e a necessidade de uma bagagem de conhecimentos e expertises que é possível de ser construída ao longo de toda a vida acadêmica por meio da organização do trabalho pedagógico destes docentes no ensino, na extensão e, como foco especial aqui, na pesquisa. 


\section{A Evolução Científica, o Desrespeito ao ser Humano e o Debate Sobre a Necessidade de uma Conduta Ética na Pesquisa}

A relação entre ciência e desenvolvimento humano e social é quase inquestionável. Tendo a compreensão de que a ciência é o caminho mais seguro para se entender o mundo e seus fenômenos (naturais, sociais, políticos, culturais...), o ser humano passou a relacionar o procedimento científico à ideia de progresso. Neste sentido, o homem paulatinamente foi se (pre)ocupando cada vez mais em fazer ciência. "Homens geniais e abnegados fizeram disso o sentido de sua vida. Instituições foram criadas e organizadas com o objetivo precípuo de produzir ciência e traduzir seus resultados para a prática” (GOERGEN, 1998, p. 01).

Todo e qualquer saber oriundo da sistematização dos conhecimentos referentes à realidade e ao ser humano perpassa por demandas e ações científicas. Assim sendo, a ciência, qualquer que seja o recorte escolhido (agrárias, exatas, humanas, sociais etc.), está relacionada, direta ou indiretamente, às relações humanas, aos processos educativos, à formação humana, à ética.

A ética, por sinal, é condição sinequa non às investigações científicas. Mas nem sempre foi assim. As situações emblemáticas que envolveram experimentos humanos no triste período da Segunda Guerra Mundial, por exemplo, nos dizem muito a respeito da degradação do ser humano em prol de uma propagada evolução da ciência. As experimentações, reconhecidamente absurdas, realizadas em seres humanos à época, que desconsideravam qualquer parâmetro de humanização, de respeito ao outro, deram origem ao conceito de Bioética, rapidamente disseminado nas áreas médicas e biológicas, e que se fundamenta nos princípios da beneficência, não-maleficência, autonomia e justiça.

No período da segunda grande guerra, os cientistas utilizavam-se de cobaias humanas que não tinham poder de decisão sobre sua participação nos estudos, pois estavam submetidas ao comando do regime nazista.

O fim da Segunda Guerra Mundial foi um marco no debate sobre ética em pesquisa. Entre as denúncias dos crimes de guerra, estavam os cruéis experimentos dos médicos nazistas. A expressão "cobaias" passou a ser utilizada para descrever a condição de vulnerabilidade dos participantes nesses experimentos, e não apenas o uso de animais não-humanos em pesquisas científicas. (...). Eram grupos oprimidos e segregados pelo ideário nazista: judeus, testemunhas-de-jeová, ciganos, minorias raciais e pessoas portadoras de deficiência (GUILHEM e DINIZ, 2008, p. 10).

Os testes incluíam experimentar novas medicações e participar de procedimentos de dissecação corpórea sem anestesia. Milhões de pessoas morreram em decorrência dessas práticas.

Prisioneiros de guerra foram forçados a beber água salgada para que se testasse a sobrevida sem água potável. Outros foram mantidos em tanques de água com baixíssimas temperaturas a fim de que se verificasse por quanto tempo sobreviveriam; em seguida, eles eram aquecidos para que se observasse sua recuperação termodinâmica. Cada experimento tinha uma justificativa no projeto nazista: o teste de termodinâmica, por exemplo, visava salvar os pilotos da 
Luftwaffe que, abatidos em voo sobreviviam à queda, mas morriam por hipotermia nas águas geladas (GUILHEM e DINIZ, 2008, p. 11).

Com o fim da guerra, dois anos após a rendição alemã, foi instaurado um tribunal de exceção, em Nuremberg/Alemanha, de modo a afastar a possibilidade de execução sumária dos envolvidos nos crimes de guerra, pois havia a preocupação de que a ação não fosse interpretada como mera vingança por parte dos países aliados. $\mathrm{O}$ intuito era de marcar simbolicamente o fim do regime nazista, ao realizar os julgamentos dos acusados de crimes contra a paz, crimes de guerra e crimes contra a humanidade.

O Tribunal de Nuremberg, formalmente denominado Tribunal Militar Internacional para a Alemanha, foi criado no final da Segunda Guerra Mundial pelos Estados Unidos da América, Reino Unido, França e União Soviética - vencedores do conflito - com o objetivo de julgar e punir 24 dos mais graúdos líderes do regime nazista, que governou a Alemanha entre 1933 a 1945, acusados de crimes contra a paz, crimes de guerra, crimes contra a humanidade e crime de conspiração para o cometimento desses crimes (ZOCOLER, 2013, p. 01).

As condenações variaram de dez anos de prisão à pena de morte por enforcamento. Entre os sentenciados, médicos que realizaram experimentações abusivas e até mesmo fatais nos prisioneiros de guerra. Contudo, foram suscitadas discussões a respeito do julgamento realizado, uma vez que, levando em consideração o autoritarismo e o estado de guerra vividos na época, a defesa argumentou perante os tribunais que os executores de tais atrocidades apenas cumpriam seu dever de obediência às ordens superiores recebidas, não podendo questioná-las. E ainda, não desrespeitaram legislação vigente à época.

Após esse cenário em que diversos cientistas protagonizaram a realização de testes que chegaram a dizimar pessoas, justificando-se na busca da evolução científica, tornou-se evidente a necessidade de regulação das pesquisas envolvendo seres humanos. E, não obstante a existência do juramento de Hipócrates realizado pela classe médica, que inclui o compromisso de não fazer o mal aos seus pacientes, os juízes responsáveis pelos julgamentos, um mês após suas decisões, entenderam ser importante editar um documento para garantia de proteção dos participantes de pesquisa. Com esse objetivo, em agosto de 1947, foi publicado o Código de Nuremberg, reunindo dez princípios básicos para a realização de pesquisas científicas com a participação de seres humanos, tendo como foco a autonomia deste participante e a proteção de seus melhores interesses:

1. O consentimento voluntário do ser humano é absolutamente essencial [...];

2. O experimento deve ser tal que produza resultados vantajosos para a sociedade $[\ldots]$

3. O experimento deve ser baseado em resultados de experimentação em animais [...]; dessa maneira, os resultados já conhecidos justificam a realização do experimento;

4. O experimento deve ser conduzido de maneira a evitar todo sofrimento físico ou mental desnecessários e danos;

5. Não deve ser conduzido qualquer experimento quando existirem razões para acreditar que pode ocorrer morte ou invalidez permanente;

6. O grau de risco aceitável deve ser limitado pela importância humanitária do problema que o experimento se propõe a resolver; 
7. Devem ser tomados cuidados especiais para proteger o participante do experimento de qualquer possibilidade de dano, invalidez ou morte, mesmo que remota;

8. O experimento deve ser conduzido apenas por pessoas cientificamente qualificadas $[\ldots]$;

9. O participante do experimento deve ter a liberdade de se retirar no decorrer do experimento [...];

10. O pesquisador deve estar preparado para suspender os procedimentos experimentais em qualquer estágio [...] (NUREMBERG, 1947, p. 181).

Curiosamente, o fato de sete dos médicos julgados terem sido condenados à pena de morte, se tornaria medida incompatível com o ideal de proteção integral dos direitos do homem que seria pactuado no ano seguinte por meio da Declaração Universal dos Direitos Humanos.

Proclamada no ano de 1948 em Assembleia Geral das Nações Unidas, a Declaração Universal dos Direitos Humanos objetivou garantir a proteção da dignidade da vida, visando à construção de uma sociedade igualitária e fraterna, fundamentada na justiça, paz e liberdade. É considerado um importante marco no que diz respeito ao reconhecimento dos direitos fundamentais de homens e mulheres. E, tendo como principal ponto de partida as barbáries cometidas até então, o referido documento convenciona que "ninguém será submetido à tortura nem a penas ou tratamentos cruéis, desumanos ou degradantes" (ONU, 1948, artigo $5^{\circ}$ ). Sendo necessária para a efetiva condenação de qualquer pessoa, a prova de sua culpabilidade demonstrada por meio "de um processo público em que todas as garantias necessárias de defesa the sejam asseguradas" (ONU, 1948, artigo 11). Destaca-se também da referida declaração, a liberdade dos indivíduos nas diferentes áreas da própria vida e no campo social, reafirmada ao longo do texto de 30 artigos.

Em relação aos estudos envolvendo pessoas, os dez pontos estabelecidos como princípios gerais pelo Código de Nuremberg foram se mostrando insuficientes para garantia dos direitos dos participantes de pesquisas. Visto que a condução de investigações desviadas do padrão ético prelecionado seguiu ocorrendo e, por isso, a Associação Médica Mundial, ao revisar o Código de Nuremberg, publicou em 1964 a Declaração de Helsinque, fornecendo orientações destinadas aos médicos e participantes de pesquisas clínicas.

O Código de Nuremberg foi revisto na $18^{\mathrm{a}}$ Assembleia da Associação Médica Mundial, em 1964, sendo aprovada a Declaração de Helsinque, que introduzia a necessidade de revisão dos protocolos por comitês independentes. A denominação Declaração de Helsinque foi mantida nas versões posteriores realizadas em Tóquio (1975), Veneza (1983), Hong Kong (1989), Somerset West (1996) e Edinburgo (2000) (MARQUES FILHO, 2007, p. 02).

A percepção do tipo de pesquisa a que se refere a Declaração de Helsinque é importante para entender historicamente a atual estrutura dos Comitês de Ética em Pesquisa, vinculados ao Ministério da Saúde, no cenário brasileiro. A Declaração de Helsinque, além de expressar a observância dos interesses do indivíduo, ainda que em detrimento do conhecimento científico que beneficiaria a coletividade, foi o primeiro documento a 
estabelecer a necessidade de prévia apreciação dos protocolos de pesquisas por um comitê de ética independente.

O desenho e a realização de cada procedimento experimental envolvendo seres humanos devem ser claramente discutidos no protocolo experimental. Esse protocolo deve ser submetido à análise, com comentários, orientações e, quando apropriado, à aprovação de um comitê de ética médica especialmente indicado, que deve ser independente do pesquisador e do patrocinador de estudo ou qualquer outro tipo de influência indevida. Esse comitê de ética independente deve estar de acordo com as regulações e leis do país no qual a pesquisa clínica será conduzida (CIOMS, 2004, p. 133).

Observa-se, portanto, naquele momento histórico, a atenção das reflexões sobre ética em pesquisa voltada exclusivamente para a área da saúde. Razão pela qual a criação dos comitês estava geralmente vinculada aos hospitais, tendo em vista suas análises estarem direcionadas para a condução de pesquisas clínicas.

Como não poderia deixar de ser, este contexto explica a crença, ainda disseminada no ambiente acadêmico, de que somente pesquisas médicas necessitam passar por um processo prévio de avaliação ética. Não é raro deparar-se com pesquisadores que somente vislumbram haver riscos para os participantes, nos estudos que propõem algum tipo de intervenção física. Contudo, veremos adiante que o conceito iniciado na bioética ampliou-se de modo a abranger os direitos dos seres humanos envolvidos em todos os tipos de investigações, sejam elas de quaisquer das áreas do conhecimento científico.

\section{A Preocupação Ética na Ciência Brasileira: um Cenário em Construção}

No Brasil, as preocupações éticas com as pesquisas envolvendo seres humanos tomaram forma a partir da Resolução $n^{\circ}$ 01, publicada pelo Conselho Nacional de Saúde (CNS) em 1988. Esta Resolução regulamentava o credenciamento de centros de pesquisas e recomendava a criação de um comitê de ética para cada centro.

Apesar da ampla abrangência dos aspectos éticos, a Resolução CNS no 01/88 era bastante específica a alguns tipos de pesquisa e profundamente ligada aos estudos desenvolvidos por profissionais das ciências da saúde. Tratava-se de normas destinadas às pesquisas da área médica. Além disso, ela definia alguns conceitos, hoje superados, a exemplo da ideia de "pesquisa sem riscos", que assim classificava as investigações que tinham como técnica a aplicação de questionários, utilização de entrevistas ou acesso a prontuários clínicos. Atualmente, entende-se que qualquer estudo com pessoas envolve riscos aos participantes, de modo que umas das principais premissas para a aprovação de um protocolo de pesquisa por um comitê de ética é exatamente que tais riscos sejam previstos, explicitados e inseridos em um planejamento de minimização e de assistência aos indivíduos pesquisados. Outros conceitos estabelecidos naquela época seriam logo atualizados.

A tentativa de especificar minuciosamente a condução dos diversos tipos de pesquisa na área da saúde demonstrada na Resolução CNS n ${ }^{\circ}$ 01/88, após revisão feita pela Comissão 
Nacional de Ética em Pesquisa (CONEP), deu lugar a uma normatização menos restrita, a Resolução CNS no 196/96. Esta nova normativa ressaltava que cada área temática de investigação e cada modalidade de pesquisa, além de respeitar os princípios éticos emanados no texto, deveriam cumprir com as exigências setoriais e regulamentações específicas.

Caberia à CONEP, portanto, a regulamentação de todo tipo de pesquisa envolvendo seres humanos, definindo como tal a "pesquisa que, individual ou coletivamente, envolva o ser humano, de forma direta ou indireta, em sua totalidade ou partes dele, incluindo o manejo de informações ou materiais" (BRASIL, 1996, item II.2). Foi a partir desta resolução que se fundamentou a necessidade da presença dos Comitês de Ética em Pesquisa no cenário científico brasileiro.

Colegiados interdisciplinares e independentes, com "munus público", de caráter consultivo, deliberativo e educativo, criados para defender os interesses dos sujeitos da pesquisa em sua integridade e dignidade e para contribuir no desenvolvimento da pesquisa dentro de padrões éticos. (BRASIL, 1996, item II.14).

Vale ressaltar, então, a estruturação que foi sendo consolidada de um sistema em rede, para acompanhamento da ética na pesquisa no Brasil. Foram criadas instâncias institucionais participantes, os CEP's. Estes, por sua vez, coordenados pela CONEP, vinculada ao CNS, estabelecendo as respectivas atribuições, regulamentações e o fluxo de aprovação de projetos de pesquisas envolvendo seres humanos.

Figura 1. Organograma do sistema CEP/CONEP

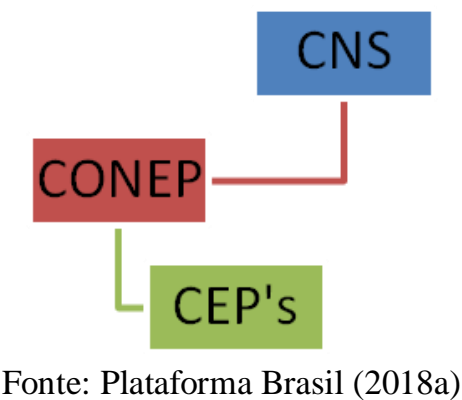

Resta demonstrado, portanto, um dos grandes avanços da normativa em questão foi reconhecer a necessidade de criação de CEP em qualquer instituição de pesquisa, e não somente quando vinculadas à Área da Saúde. Representou medida importante na regulamentação e disseminação desses colegiados por todo o país. Além disso, vale ressaltar a explicitação de quatro pontos fundamentais à eticidade da/na pesquisa envolvendo seres humanos no que tange à autonomia, à beneficência, à não-maleficência e à justiça e equidade, sendo exigências éticas e científicas fundamentais:

1. consentimento livre e esclarecido dos indivíduos-alvo e a proteção a grupos vulneráveis e aos legalmente incapazes. Neste sentido, a pesquisa envolvendo seres humanos deverá sempre tratá-los em sua dignidade, respeitá-los em sua autonomia e defendê-los em sua vulnerabilidade; 
2. ponderação entre riscos e benefícios, tanto atuais como potenciais, individuais ou coletivos, comprometendo-se com o máximo de benefícios e o mínimo de danos e riscos;

3. garantia de que danos previsíveis serão evitados;

4. relevância social da pesquisa com vantagens significativas para os sujeitos da pesquisa e minimização do ônus para os sujeitos vulneráveis, o que garante a igual consideração dos interesses envolvidos, não perdendo o sentido de sua destinação sócio-humanitária (BRASIL, 1996, item III.1).

Como já se previa a necessidade de revisões periódicas, a Resolução CNS no 196 foi revogada após a publicação de nova normativa em 2012, a Resolução CNS no 466. Diminuindo de 33 para 12 páginas, o novo documento sistematizou de maneira mais concisa a regulamentação de pesquisas envolvendo seres humanos no contexto brasileiro. A separação dos aspectos procedimentais e administrativos, previstos para serem tratados em Norma Operacional do próprio CNS, também contribuiu para esse feito. A Norma Operacional CNS no 001 foi publicada no ano de 2013 e dispõe sobre a organização e funcionamento do Sistema CEP/CONEP, e sobre os procedimentos para submissão, avaliação e acompanhamento de pesquisas envolvendo seres humanos no Brasil. Há o destaque, inclusive, de que estas propostas de pesquisa devem ser submetidas ao Sistema CEP/CONEP por meio da Plataforma Brasil.

A Plataforma Brasil é uma base nacional e unificada de registros de pesquisas
envolvendo seres humanos para todo o sistema CEP/CONEP. Ela permite que as
pesquisas sejam acompanhadas em seus diferentes estágios - desde sua submissão
até a aprovação final pelo CEP e pela CONEP, quando necessário - possibilitando
inclusive o acompanhamento da fase de campo, o envio de relatórios parciais e dos
relatórios finais das pesquisas (quando concluídas). O sistema permite, ainda, a
apresentação de documentos também em meio digital, propiciando ainda à
sociedade o acesso aos dados públicos de todas as pesquisas aprovadas. Pela
Internet é possível a todos os envolvidos o acesso, por meio de um ambiente
compartilhado, às informações em conjunto, diminuindo de forma significativa o
tempo de trâmite dos projetos em todo o sistema CEP/CONEP (PLATAFORMA
BRASIL, 2018a).

Em virtude do processo histórico aqui descrito e, ainda, considerando a configuração destacada anteriormente, com vinculação ao Ministério da Saúde, o sistema CEP/CONEP tem sido alvo de variadas críticas, especialmente por parte dos pesquisadores das áreas de Ciências Humanas e Sociais Aplicadas. Isso porque as especificidades das pesquisas em saúde foram enormemente contempladas nas normatizações que foram sendo implementadas ao longo dos anos, enquanto as pesquisas que utilizam metodologias características das humanas e sociais aplicadas foram regulamentadas apenas recentemente, no ano de 2016, por meio da Resolução CNS nº 510.

A disparidade entre as diversas áreas de conhecimento também pode ser facilmente verificada na submissão de protocolos via Plataforma Brasil, visto que muitos dos campos que são solicitados preenchimento aplicam-se exclusivamente a determinados tipos de pesquisa. A título de exemplo, é possível citar a etapa de preenchimento $\mathrm{n}^{\circ} 03$, chamada Desenho de Estudo/Apoio Financeiro, que tem quase todos os itens direcionados para pesquisas em saúde (Condições de saúde ou problemas estudados, Descritos gerais para as 
condições de saúde, Classificação internacional de doenças etc.). Essa etapa específica é desabilitada na escolha da Grande Área do Conhecimento (etapa de preenchimento $\mathrm{n}^{\mathrm{o}}$ 02). Entretanto, em alguns espaços de preenchimento obrigatório que não são desabilitados automaticamente, é necessário preencher com a expressão "não se aplica".

Há outras instruções, como no caso do campo "Desenho" em que a indicação do pesquisador deve ser "vide metodologia", e ainda, no item "tamanho da amostra no Brasil", é possível inserir apenas o número " 0 " quando o tipo de metodologia não prevê o número de participantes, pois nesse campo a Plataforma aceita somente números, cabendo ao pesquisador inserir esse esclarecimento na metodologia da pesquisa. As reclamações aos CEP's são recorrentes, demandando tarefa constante de capacitação junto aos pesquisadores, cumprindo, portanto, o papel educativo que lhes cabe. Felizmente, há indicações de avanços, pois existe um trabalho de reconfiguração da Plataforma Brasil em andamento, a fim de contemplar as especificidades na submissão de protocolos de outras áreas de conhecimento, inclusive das Ciências Humanas e Sociais.

Apesar das críticas que se fazem ao sistema, principalmente em razão da tarefa excessivamente burocrática que impõe, é necessário reconhecer seus aspectos positivos. Até 2012, a tramitação dos projetos de pesquisa realizada por meio físico dificultava consideravelmente a obtenção de pareceres pelos pesquisadores. Destaca-se que a Plataforma Brasil, uma base de dados nacional, obrigatória em todos os CEP's, permitiu maior rapidez na dinâmica de análise ética; deu mais liberdade aos pesquisadores e relatores, tendo em vista a possibilidade de acesso em qualquer local e horário; aumentou a garantia de sigilo e privacidade dos documentos dos protocolos de pesquisa; e, uniformizou e deu mais transparência aos procedimentos e critérios de apreciação dos projetos de pesquisa com seres humanos.

A Plataforma também facilitou o acesso às Normativas e Resoluções, aos manuais e às informações dos Comitês de Ética espalhados pelo Brasil, entre outras funcionalidades. Também é possível atendimento via chat em caso de problemas com a ferramenta. Sim, os problemas aparecem, até com certa frequência. Desde pesquisadores que não conseguem realizar o próprio cadastro ou encontrar o parecer do CEP, até as dificuldades iniciais do próprio CEP com o sistema quando se trata, por exemplo, de submissão de relatório de pesquisa ou emenda. Emenda, vale ressaltar, é toda proposta de modificação ao projeto original, encaminhada ao Sistema CEP/CONEP pela Plataforma Brasil, com a descrição e a justificativa das alterações (PLATAFORMA BRASIL, 2018b).

Termos como "parecer consubstanciado" passam a fazer parte do cotidiano da pesquisa universitária. Esta nova dinâmica acadêmica, que envolve novos aprendizados e novas sistematizações do saber e das práticas pedagógicas, tem mostrado que as reconfigurações nestes espaços de atuação de servidores técnicos administrativos e professores universitários são desafiadoras, tanto no que diz respeito ao processo epistemológico da pesquisa quanto à operacionalidade de como se fazer esta pesquisa que envolve pessoas no processo de investigação científica. Dessa maneira, percebe-se que o

\begin{tabular}{l|c|c|c|c|c} 
(c) Rev. Inter. Educ. Sup. & Campinas, SP & v.6 & $1-20$ & $\mathrm{e} 020033$ & 2020
\end{tabular}


processo perpassa muito pelo empenho de cada CEP, já que esse é um dos pontos precários deixados pela CONEP.

Tudo começa desde o registro inicial de um CEP, onde não há uma capacitação efetiva por parte da referida comissão nacional. De modo que cada comitê tem, a priori, o desafio de desbravar seus próprios caminhos, a partir de um treinamento inicial dado por um comitê próximo que já possua alguma experiência. Dentre as ferramentas para esse feito estão as diretrizes estabelecidas pela CONEP, a possibilidade de contato com ela via e-mail para solucionar dúvidas e a predisposição da comunidade científica objetivando a criação de um sistema de análise ética fortalecido. Além disso, é relevante uma aproximação entre os comitês locais para que se tenha uma rede dialogável à disposição.

De forma sintética, são três os documentos que garantem uniformidade no modo de agir dos Comitês de Ética - Resoluções CNS 466/2012 e 510/2016 e Norma Operacional CNS 001/2013. Entretanto, a discussão acadêmica se faz sobre os resultados alcançados a partir desses procedimentos, que muitas vezes diferem enormemente entre si. Por isso é importante desmistificar a análise ética que compete aos CEP's:

A avaliação a ser feita pelo Sistema CEP/CONEP incidirá sobre os aspectos éticos dos projetos, considerando os riscos e a devida proteção dos direitos dos participantes da pesquisa.

A avaliação científica dos aspectos teóricos dos projetos submetidos a essa Resolução compete às instâncias acadêmicas específicas, tais como comissões acadêmicas de pesquisa, bancas de pós-graduação, instituições de fomento à pesquisa, dentre outros. Não cabe ao Sistema CEP/CONEP a análise do desenho metodológico em si.

A avaliação a ser realizada pelo Sistema CEP/CONEP incidirá somente sobre os procedimentos metodológicos que impliquem em riscos aos participantes (BRASIL, 2016, art. 25).

Apesar da pertinência da normatização existente, percebem-se alguns vácuos no transcorrer dos trabalhos dos comitês. Nesta hora, a comunicação permanente do CEP com a CONEP é de fundamental importância, com o intuito de sanar questionamentos relacionados a situações não contempladas nos documentos existentes. Essa aproximação é essencial para o trabalho dos comitês, visto que integram um sistema, não obstante serem independentes nas instituições que os abrigam. Ocorre que o distanciamento que estas instâncias possuem junto à CONEP, por vezes, é um obstáculo a ser transposto por cada comitê, de acordo com suas particularidades. Sensibilizar e, progressivamente, desenvolver uma consciência crítica e comprometida com a ética em pesquisas científicas é um desafio não só junto aos pesquisadores, mas também perante os gestores das instituições proponentes de pesquisas no Brasil. Isso porque o bom funcionamento de cada CEP depende dessa integração.

É preciso haver boa vontade por parte das instituições para prover desde as exigências mais básicas feitas pela CONEP, como sala, funcionário administrativo exclusivo e recursos materiais, até a designação de membros que deverão acrescentar às suas atividades habituais, as análises de protocolos de pesquisa e a presença nas reuniões periódicas. Se a instituição não "veste a camisa", a missão do CEP torna-se penosa e pouco produtiva. É preciso garantir 
autonomia para os colegiados, sob pena de manter um comitê meramente formalista, que não atende o interesse social na proteção dos sujeitos participantes de pesquisas no Brasil.

Eventuais conflitos de interesse também devem ser afastados do exercício que compete ao sistema CEP/CONEP, por isso pressupõe-se a atuação voluntária dos membros, tenham eles entrado por meio de candidatura ou indicação. A duração e a forma de renovação do mandato dos membros é um dos pontos que devem ser disciplinados em Regimento Interno na criação de um CEP. Além disso, há também a responsabilidade de capacitação contínua, inclusive com necessidade de registro e encaminhamento à CONEP nos relatórios enviados semestralmente. Por sua vez, esses relatórios também devem conter, entre outras exigências, o detalhamento dos projetos analisados e as condições de funcionamento.

A burocracia e a sistemática relacionada à criação e ao efetivo funcionamento de um Comitê de Ética, por sinal, podem ser alguns dos fatores para a existência de um cenário acadêmico em que muitas Instituições de Ensino Superior (IES), por exemplo, não encaram a tarefa de implantação. Ainda assim, tendo em vista o caráter social, independente e de interesse público das análises éticas, há a possibilidade de qualquer projeto ser apreciado por um CEP, ainda que a instituição proponente não possua um. Nestes casos, especificamente, a indicação é realizada via Plataforma Brasil pela CONEP, gerando assim um aumento no trabalho desses colegiados, inicialmente voltados para projetos da própria instituição mantenedora daquele comitê.

Atualmente, a Plataforma Brasil indica a existência de 817 Comitês de Ética no Brasil. Desse total, 380 estão localizados na região sudeste, 163 no nordeste, 148 no sul e 63 tanto no centro-oeste quanto no norte do país, como mostra o gráfico a seguir:

Gráfico 1. Distribuição dos Comitês de Ética em Pesquisa no Brasil

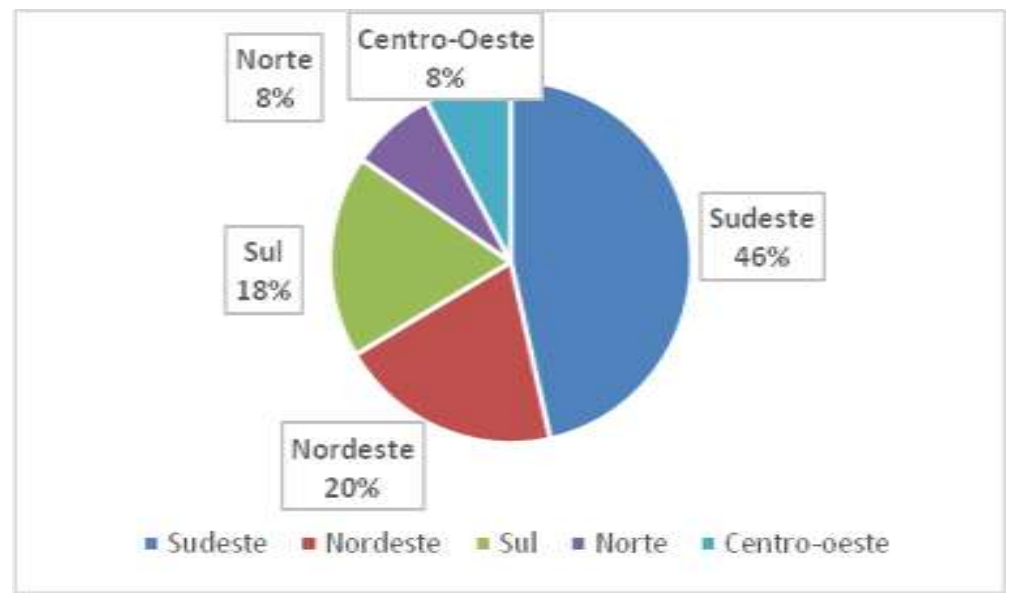

Fonte: Plataforma Brasil (2018a)

Dos 63 pertencentes à região norte, 09 fazem parte do cenário tocantinense, sendo 04 deles mantidos por instituições públicas. Na capital, Palmas, há 04 Comitês de Ética em funcionamento, apenas um vinculado a Instituição de Ensino Superior privada. Os outros três 
são mantidos pela Fundação Universidade Federal do Tocantins (UFT), pelo Instituto Federal de Educação Ciência e Tecnologia (IFTO) e pela Universidade Estadual do Tocantins (UNITINS). Os conhecimentos construídos no processo de criação do CEP UNITINS, atrelados à formação continuada e complementar dos membros que compõem o referido comitê para suas atuações enquanto docentes da universidade, serão foco da seção a seguir.

\section{A Atuação do CEP UNITINS e a Criação de um Espaço de Formação Docente: Fazer Pedagógico entre os Protocolos de Pesquisa Científica}

Diferente dos tipos de pesquisa que inicialmente eram o único foco do sistema CEP/CONEP - estudos envolvendo novos medicamentos, vacinas e armazenamento de material biológico, os protocolos apreciados pelo Comitê de Ética em Pesquisa da UNITINS partem de outra realidade. A universidade possui nove cursos de graduação presenciais, distribuídos em quatro campi do estado do Tocantins - Araguatins, Augustinópolis, Dianópolis e Palmas. De modo que, na inexistência de um programa de pós-graduação stricto sensu, a maior parte das pesquisas analisadas diz respeito aos projetos do Programa de Iniciação Científica e dos Trabalhos de Conclusão de Curso. Assim, a partir da demanda do curso de Serviço Social, a necessidade de um CEP foi colocada em pauta no ano de 2015, quando foram formados os primeiros grupos de professores pesquisadores para discussões nesse sentido.

Contrariamente aos impulsos que deram origem ao sistema CEP/CONEP, na UNITINS, a 'cobrança' inicial para criação do Comitê partiu da área das Ciências Sociais Aplicadas. E após a criação, o Comitê teve rápida adesão do curso de Enfermagem, como era esperado. De outro modo, transcorridos pouco mais de três anos de efetivo funcionamento do CEP UNITINS, ainda percebe-se a ausência de submissões de pesquisas dos cursos de Administração, Ciências Contábeis, Direito, Engenharia Agronômica, Letras, Pedagogia e Sistemas de Informação. Essa situação justifica bem a presença do termo "educativo" na descrição do papel do CEP, pois a incorporação da fase de análise ética no processo de investigação científica pode enfrentar resistências da comunidade acadêmica. Seja por uma postura defensiva dos pesquisadores, que se sentem desconfortáveis ao imaginar a exposição de seu projeto de pesquisa à plenária do Comitê de Ética, ou por simples desinformação, visto que muitos pesquisadores ainda têm consigo o conceito de "pesquisa sem risco" formulado pela Resolução CNS 01/1988.

Desta forma, entende-se a aceitação e adesão da comunidade acadêmica como fruto de um processo que se iniciou com a criação do CEP pela universidade e tem continuidade com o trabalho de sensibilização contínuo do comitê na instituição, educando para uma prática científica baseada em preceitos éticos. Em nosso trabalho à frente do CEP, observamos que a assimilação destas questões é simples e rápida para alguns pesquisadores, visto que tiveram contato com um Comitê de Ética durante suas graduações, especializações, mestrados e doutorados. No entanto, também percebemos certa resistência por parte de outros pesquisadores que, a princípio, não entendiam o porquê da necessidade de submeter seus 
trabalhos ao colegiado do CEP. É com base neste segundo cenário que o CEP pode mostrar seu valor, desempenhando o papel educativo que lhe cabe. Por isso, reuniões com os departamentos institucionais, colegiados de curso e associações de estudantes, projetos de extensão, divulgação das reuniões ordinárias e publicização das atividades realizadas são tão importantes para que a presença dos CEP's no contexto universitário se torne algo conhecido de tal modo que a comunidade acadêmica tenha consciência do seu papel e da sua importância em defesa da ética no exercício da prática científica.

Não se pode negar que há um pouco de burocracia envolvida na dinâmica de submissão dos projetos por parte dos pesquisadores. A própria relação com o sistema virtual, com o já mencionado distanciamento da CONEP, é em alguns casos fator dificultante. Somam-se a isso, as questões materiais e financeiras não favoráveis na maioria das instituições de ensino públicas, e até mesmo a falta de capital humano, visto que numa universidade ainda pequena como a UNITINS, no que tange à quantidade de professores, tornar-se membro do CEP pode representar uma sobrecarga de trabalho.

Inseridos no processo de criação do CEP, verificamos que a falta de treinamento adequado e frequente é um problema. A Plataforma Brasil, sem dúvida, possui inúmeras vantagens se comparada à tramitação de protocolos em papel. No entanto, é preciso certa dose de boa vontade para a tarefa, em parte, autodidata de trabalhar com a ferramenta. Também levamos tempo para acertar os critérios de avaliação ética e elaborar pareceres com o mínimo de uniformidade necessária. O fluxo de tramitação ajuda nisso, já que todos os pareceres passam necessariamente pelo crivo final da coordenação do CEP. Além disso, é preciso considerar que essa construção é feita gradualmente a partir das discussões em plenária.

Acreditamos que o envolvimento à rotina de atividades inerentes aos comitês de ética proporciona uma ampliação da interpretação do papel profissional do professor universitário, com destaque aos aspectos relativos à postura investigativa necessária para o exercício de uma prática pedagógica autônoma e responsável. Neste sentido, Severino (2009, p. 120) nos ensina que "a prática científica na universidade exige mediações curriculares que articulem uma legitimação político-educacional do conhecimento, sua fundamentação epistemológica, uma estratégia didático-metodológica e uma metodologia técnico-aplicada”. E, para nós, a estrutura de organização e funcionamento e os próprios trâmites de apreciação ética dos projetos de pesquisa protocolados ali ajudam a construir esse cenário mencionado.

O comitê de ética atua, mesmo que indiretamente, como um espaço de formação do professor que nele atua. Tendo a ciência de que a vida do professor universitário se faz em torno do mundo da pesquisa, um CEP pode reforçar o entendimento da necessidade da prática da pesquisa no contexto pedagógico-acadêmico, pois ela colabora tanto no ato de ensinar quanto no ato de aprender. "Professores e alunos precisam manter-se envolvidos com a pesquisa, por dois motivos: primeiro, para acompanhar o desenvolvimento histórico do conhecimento; segundo, porque o conhecimento só se realiza como construção de objetos" (SEVERINO, 2009, p. 121). Desta maneira, a prática pedagógica, especificamente o processo

\begin{tabular}{l|c|c|c|c|c} 
C Rev. Inter. Educ. Sup. & Campinas, SP & v.6 & $1-20$ & $\mathrm{e} 020033$ & 2020 \\
\hline
\end{tabular}


de ensino e aprendizagem, se concretiza sob a percepção do questionamento e da investigação de objetos de estudo seja qual for a área do conhecimento.

Temos, então, de repensar a relação que é estabelecida entre os sujeitos e seus objetos de estudos. E os exemplos observados nos protocolos de pesquisa submetidos aos comitês de ética, na elaboração de um parecer ou nos relatos de outros pareceres advindos dos colegas que ali atuam, são significativos para se perceber como ocorre a construção científica em nosso país. Aporte teórico, metodologia e recursos materiais são importantes, sim, à investigação desejada. Contudo, é necessário ir além. Para lidar com o conhecimento científico, o pesquisador precisa também apoiar-se em paradigmas epistemológicos e assumir o sentido da pesquisa numa perspectiva histórica onde é "entendida como processo de construção dos objetos do conhecimento e a relevância que a ciência assume em nossa sociedade" (SEVERINO, 2009, p. 125).

A ideia aqui defendida é a da associação entre a pesquisa e o exercício da docência, de tal modo que possamos analisar essa relação como um processo formativo permanente na vida do professor perante uma organização didático-pedagógica em que o ensino se aproxima da pesquisa e esta, por sua vez, contextualiza-se em uma prática específica no universo acadêmico: a de análise ética de protocolos submetidos aos comitês de ética. Assim, seguindo a perspectiva de Franco (2000, p. 67), tendo por base que o processo de pesquisa interliga pessoas, instituições e comunidade, enxergamos também a universidade como

um serviço público, pois atende às necessidades da comunidade, e a pesquisa como um dos serviços da universidade, [haja vista que] a produção do conhecimento tem significado social. Para a mediação da pesquisa no processo formativo, a justificação decorre do qualificativo processual de busca da verdade, acrescido do relativismo da verdade face às inúmeras lentes interpretativas que incidem sobre a realidade. A mediação da pesquisa sobre o ensino se faz também presente na perspectiva de um processo permanente de formação do professor, auxiliando-o a redirecionar os caminhos.

A formação docente está intimamente ligada ao desenvolvimento profissional dos professores. Envolve, então, uma perspectiva institucional e uma perspectiva pessoal do professor. De acordo com Soares e Cunha (2010, p. 35),

\footnotetext{
$\mathrm{Na}$ perspectiva institucional, o desenvolvimento profissional pode ser entendido como um conjunto de ações sistemáticas que visam alterar a prática, as crenças e os conhecimentos profissionais dos professores, portanto vai além do aspecto informativo. (...) Na perspectiva pessoal, o desenvolvimento profissional se projeta por uma disposição interna e uma postura de busca permanente de crescimento pessoal e profissional, disposição de refletir coletivamente sobre as práticas, atitudes e crenças individuais e coletivas, abertura para mudança.
}

A formação do professor, principalmente aquela que ocorre durante o exercício da profissão, se dá num processo de reflexão sobre sua prática com o objetivo de reconstruir sua identidade pessoal e profissional e, assim, vislumbrar novas possibilidades para o desenvolvimento profissional. Aliás, "o aprender contínuo é essencial e se concentra em dois 
pilares: a própria pessoa, como agente, e a escola, como lugar de crescimento profissional permanente" (NÓVOA, 2002, p. 23).

São esses olhares que direcionamos à experiência construída pelo CEP UNITINS, a partir do momento em que os professores demonstram voluntariamente o desejo em atuar no referido comitê e o próprio espaço educativo que se configura este comitê, haja vista a troca de experiências, a construção de novos conhecimentos, a partilha de novos saberes, enfim, atividades que possibilitam aos professores participantes desenvolverem-se profissionalmente.

Sendo parte integrante de uma sociedade que tem passado nas últimas décadas processos intensos e velozes de transformações, incluindo de modo especial o campo educacional, ao professor universitário do século XXI são lançados novos desafios à sua atuação e, consequentemente, desafios à própria gestão acadêmica das instituições de ensino superior.

Acompanhamos, então, Borghetti et al. (2017) quando defendem que o trabalho pedagógico docente aproxima-se com as práticas gerenciais de uma IES, até mesmo pela compreensão de que ser docente é fazer-se docente num processo de construção identitária baseado nos atos de ensinar, formar e transformar o outro e o mundo. Para tanto, a leitura da necessidade de rompimento de alguns paradigmas se torna ponto fundamental no contexto de formação/atuação docente. "A crise do profissionalismo, que coloca em xeque a maneira de ensinar, discutindo a necessidade de desenvolver o ensino voltado para a realidade concreta, traz, por sua vez a dicotomia entre a experiência docente e a experiência aplicada dos docentes" (BORGHETTI et al., 2017, p. 02).

Vemos que as realidades trazidas pelos projetos de pesquisa protocolados nos comitês de ética trazem aos professores que ali estão questões que dizem respeito à sociedade contemporânea em suas múltiplas facetas, suscitando encaminhamentos didático-pedagógicos às aulas destes profissionais de maneira tal que reflitam em prol da formação de novos comportamentos e procedimentos destes sujeitos que estão intimamente ligados ao processo de construção epistemológica sobre as práticas educativas, em especial o ensino e a aprendizagem, nas IES.

"A docência é uma atividade complexa. Só quando for reconhecida essa complexidade, poderemos avançar em processos de qualificação mais efetivos", menciona Cunha (2008). Reconhecemos, sim, essa complexidade que envolve o trabalho do professor e, em especial, destacamos que ao professor universitário no Brasil, hoje, é exigido saberes específicos que se constroem na justaposição da teoria com a prática. Em outras palavras, no encontro da pesquisa com o ensino. Nada mais promissor, então, que o espaço de trabalho dos comitês de ética em pesquisa para se materializar essa percepção acadêmica.

Sabemos bem que a formação dos professores universitários no Brasil não está sustentada na exigência de conhecimentos pedagógicos específicos à docência. São

\begin{tabular}{l|l|l|l|l|l}
\hline C C Rev. Inter. Educ. Sup. & Campinas, SP & v.6 & $1-20$ & e020033 & 2020
\end{tabular}


valorizados, especificamente, saberes que estruturam as competências e habilidades exigidas nos cursos de pós-graduação stricto sensu, a saber, aspectos pertinentes ao perfil de pesquisadores que lidam cotidianamente com projetos de pesquisa. Entendemos que é preciso ir além.

Os conhecimentos pedagógicos são imprescindíveis àqueles docentes que se preocupam em criar situações de aprendizagem aos seus alunos condizentes às tendências pedagógicas contemporâneas, onde os conteúdos estudados são ressignificados perante a realidade vivida e projetada nas perspectivas pessoal e profissional dos envolvidos na prática educativa. $\mathrm{O}$ docente precisa ficar atento para que o seu trabalho em sala de aula não fique rotulado como uma mera execução burocrática de um planejamento definido e controlado por coordenadores de curso e/ou técnicos de educação, conforme sinaliza Ferreira (2010, p. 91):

\footnotetext{
Para que o professor não caia nas armadilhas da burocratização pedagógica, é necessário um conhecimento pedagógico geral, como, por exemplo, planejamento do conteúdo, organização do tempo, material, espaço de aprendizagem e do grupo. Inclui, ainda, um conhecimento sobre Desenvolvimento Humano, História e Filosofia, e sobre os principais aspectos das leis educacionais.
}

Concordamos com a autora em questão, no que diz respeito à caracterização da ação docente no nível superior da educação brasileira, já que não existe uma única didática que atenda a cada um dos cursos de graduação existentes no país. Assim, a capacidade social e cultural do docente conta muito no seu exercício profissional. Dialogar com o mundo e estender seus conhecimentos específicos por área de saber à realidade concreta da vida dos estudantes, equilibrando o conflito entre a pluralidade política da ciência e o conhecimento técnico especializado, se torna um dos grandes desafios a ser vencido pelos docentes universitários na atualidade.

\section{Considerações Finais}

Qualquer reflexão sobre formação de professores universitários no Brasil envolve questões relativas à pesquisa, à prática pedagógica e ao contexto sociopolítico que permeia o seu exercício profissional. Desta maneira, o percurso de vida pessoal, a formação inicial em nível de graduação, o afunilamento dos estudos em nível de pós-graduação, além dos desafios, das competências e dos saberes necessários ao ato de lecionar foram trazidos neste artigo para que compuséssemos o enredo da temática a respeito dos comitês de ética em pesquisa enquanto espaços de formação continuada dos docentes que atuam no ensino superior.

Com conhecimento científico e a construção de habilidades para superar os desafios encontrados na rotina de trabalho de um CEP, que aprecia eticamente os protocolos de pesquisas que envolvem seres humanos, concluímos que os professores universitários possuem um lugar a mais para a (auto)reflexão sobre o que é ser professor na sociedade atual e quais são os elementos constituintes necessários que compõem a formação acadêmicopedagógica.

\begin{tabular}{l|c|c|c|c|c} 
(C) Rev. Inter. Educ. Sup. & Campinas, SP & v.6 & $1-20$ & $\mathrm{e} 020033$ & 2020 \\
\hline
\end{tabular}


O planejamento de uma pesquisa assemelha-se, claro, com o planejamento de uma aula. Tema, justificativa, objetivos, metodologia, recursos, referencial teórico, entre outros, são itens que perpassam nas duas esferas acadêmicas. Atrelado a isso, as análises dos protocolos submetidos na Plataforma Brasil colaboram no alargamento da visão de mundo dos professores membros dos comitês de ética. E não só nos aspectos científicos. A interdisciplinaridade configurada nestes CEP's colabora nos debates que ocorrem nas reuniões de colegiado, partindo da exposição da análise feita dos protocolos de pesquisa por parte do relator responsável, de tal forma que tenhamos um ambiente de problematização da realidade social.

É a dimensão política, então, que mais nos chama a atenção no processo de formação continuada deste professor membro de um comitê de ética em pesquisa. Contudo, a atuação que ele desempenha ali se atrela também à dimensão didático-pedagógica que é efetivada na prática de ensino em sala de aula. Clareza na estrutura da aula com boa escolha dos caminhos que serão percorridos, apoio teórico-material pertinente àquilo que será estudado e relevância dos conteúdos que serão trabalhados ratificam a importância do papel do professor universitário para a construção de uma aprendizagem significativa.

\section{Referências}

BORGHETTI, Raquel. O desafio da docência no ensino superior: uma abordagem baseada na transição de paradigmas e a na crise do profissionalismo. XVII Colóquio internacional de gestão universitária. Mar Del Plata, Argentina, nov. 2017.

BRASIL. Ministério da Saúde. Conselho Nacional de Saúde. Resolução CNS nº 01/1988. Normas de pesquisa em saúde. Brasília. Conselho Nacional de Saúde. Ministério da Saúde, 1988.

BRASIL. Ministério da Saúde. Conselho Nacional de Saúde. Comissão Nacional de Ética em Pesquisa. Resolução CNS no 196/1996. Diretrizes e normas regulamentadoras de pesquisas envolvendo seres humanos. Brasília, 1996.

BRASIL. Ministério da Saúde. Conselho Nacional de Saúde. Comissão Nacional de Ética em Pesquisa. Resolução CNS no 466/2012. Diretrizes e normas regulamentadoras de pesquisas envolvendo seres humanos. Brasília, 2012.

BRASIL. Ministério da Saúde. Conselho Nacional de Saúde. Comissão Nacional de Ética em Pesquisa (CONEP). Norma Operacional CNS n⿳0 01/2013. Organização e funcionamento do Sistema CEP/CONEP e os procedimentos para submissão, avaliação e acompanhamento da pesquisa e de desenvolvimento envolvendo seres humanos no Brasil. Brasília, 2013.

BRASIL. Ministério da Saúde. Conselho Nacional de Saúde. Comissão Nacional de Ética em Pesquisa. Resolução CNS no 510/2016. Normas aplicáveis a pesquisas em Ciências Humanas e Sociais cujos procedimentos metodológicos envolvam a utilização de dados diretamente obtidos com os participantes ou de informações identificáveis ou que possam acarretar riscos maiores do que os existentes na vida cotidiana. Brasília, 2016. 
CIOMS, Conselho de Organizações Internacionais de Ciências Médicas. Diretrizes éticas internacionais para a pesquisa biomédica em seres humanos. São Paulo: Loyola, 2004.

CUNHA, Maria Isabel. Formação docente e inovação: epistemologias e pedagogias em questão. In: ENCONTRO NACIONAL DE DIDÁTICA E PRÁTICA DE ENSINO, 14., 2008. Porto Alegre. Anais... Recife: Edições Bagaço, 2008. v. 1. p. 465-476.

FERREIRA, Lúcia de Fátima Guerra; ZENAIDE, Maria de Nazaré Tavares, PEREIRA, Célia Maria da Costa; SILVA, Itamar Nunes da (org). Direitos Humanos na Educação Superior: subsídios para a Educação em Direitos Humanos nas Ciências Sociais. João Pessoa: Editora Universitária da UFPB, 2010.

FERREIRA, Valéria Silva. As especificidades da docência no ensino superior. Rev. Diálogo Educ., Curitiba, v. 10, n. 29, p. 85-99, jan./abr. 2010.

FRANCO, Maria Estela Dal Pai. Comunidade de conhecimento, pesquisa e formação do professor do ensino superior. In: MOROSINI, Marília Costa (org.). Professor do ensino superior: identidade, docência e formação. Brasília: Instituto Nacional de Estudos e Pesquisas Educacionais, 2000. p. 61-74

GOERGEN, Pedro. Ciência, sociedade e universidade. Educação \& Sociedade. Campinas, vol. 19, n. 63, ago. 1998. Disponível em:

http://www.scielo.br/scielo.php?script=sci arttext\&pid=S0101-73301998000200005. Acesso em: 02 jan. 2019.

GUILHEM, Dirce; DINIZ, Débora. O que é ética em pesquisa. São Paulo: Brasiliense, 2008.

HELSINQUE. Princípios éticos para as pesquisas médicas em seres humanos adotados pela $18^{a}$ Assembleia Médica Mundial Helsinque, Finlândia, junho de 1964.

MARQUES FILHO, José. Ética em pesquisa: dez anos da resolução CNS 196/96. Revista Brasileira de Reumatologia. São Paulo, vol.47, n.1, p. 2-3, jan./fev. 2007. Disponível em: http://www.scielo.br/scielo.php?script=sci_arttext\&pid=S0482-50042007000100002. Acesso em; 12 dez. 2018.

NÓVOA, António. Formação de professores e trabalho pedagógico. Lisboa: Educa, 2002.

NUREMBERG. Julgamento de criminosos de guerra perante os Tribunais Militares de Nuremberg. Control Council Law, Nuremberg, v. 10, n. 02, p. 181-182, 1947.

ONU. Declaração universal de direitos humanos. Assembleia Geral das Nações Unidas em Paris. Paris, 1948.

PIOVESAN, Flávia. Temas de Direitos Humanos. 9.ed. São Paulo: Saraiva, 2016.

PLATAFORMA BRASIL. Sobre a Plataforma Brasil. Disponível em: http://plataformabrasil.saude.gov.br/login.jsf. Acesso em: 10 dez. $2018 \mathrm{a}$.

\begin{tabular}{l|l|l|l|l|l} 
(C) Rev. Inter. Educ. Sup. & Campinas, SP & v.6 & $1-20$ & $\mathrm{e} 020033$ & 2020 \\
\hline
\end{tabular}


PLATAFORMA BRASIL. Manual do usuário pesquisador. Disponível em: http://plataformabrasil.saude.gov.br/login.jsf. Acesso em: $10 \mathrm{dez} .2018 \mathrm{~b}$.

SARLET, Ingo Wolfgang. Dignidade (da pessoa) humana e direitos fundamentais na Constituição Federal de 1988. 10.ed. Porto Alegre: Livraria do Advogado, 2015.

SEVERINO, Antonio Joaquim. Docência universitária: a pesquisa como princípio pedagógico. Revista @mbienteeducação, São Paulo, v. 2, n. 1, p. 120-128, jan/jul 2009.

SOARES, Sandra Regina; CUNHA, Maria Isabel da. Formação do professor: a docência universitária em busca de legitimidade. Salvador: EDUFBA, 2010.

ZOCOLER, Marcos Rafael. O Tribunal Militar Internacional para a Alemanha - Tribunal de Nuremberg. Jus Navigandi, São Paulo, p. 1-6, out.2013. Disponível em:

https://jus.com.br/artigos/25599/o-tribunal-militar-internacional-para-a-alemanha-tribunal-denuremberg. Acesso em: 15 abr. 2019. 